\title{
Sociological Diagnostics of Collective Representations of Russians in the Context of Migration Dynamics
}

\author{
Svetlana Guzenina ${ }^{1},{ }^{*}$ Tatyana Kuznetsova ${ }^{2}$, Nina Volkova ${ }^{3}$ \\ ${ }^{1}$ Derzhavin Tambov State University, Russia \\ ${ }^{2}$ Moscow State University, Russia \\ ${ }^{3}$ Moscow Aviation Institute (National Research University), Russia \\ *Email: gyzenina39@gmail.com
}

\begin{abstract}
The article summarises the sociological data of empirical measurements conducted in Russia during 2012 2019 on the issue of collective perceptions of Russians regarding labour migrants, and presents the results of the author's 2019 sociological survey.

A comparative analysis of publications and experimental data on the topic allows us to conclude that the problems of adaptation and integration of migrants into the accepted multi-ethnic space of Russia at the present stage are studied comprehensively.

Based on the author's empirical research, it is noted that Russians recognise the contribution of migrants to the country's economy by filling the shortage of workers in unattractive/low-paid jobs. Still, the attitude towards labour migrants remains wary for several reasons, the main of which are the low level of newcomers education, unwillingness to get acquainted with the language and culture of the host society, as well as the negative image of migrants formed in the media.
\end{abstract}

Keywords: Labour migration, Labour market, Collective views of Russians.

\section{INTRODUCTION}

There are several stages in the dynamics of foreign workers labour migration to Russia. The first stage (1994-1996) - a period of accelerated growth of labour migration to Russia, which was facilitated by the transformation of the political and economic system. The period 1997-2000 reduction in the influx of foreign labour (by more than a quarter). The third stage (20012008 ) is characterised by a sharp increase in the number of foreign workers who arrived for temporary work and worked under contracts and labour agreements. The fourth stage began in 2009 and is associated with the global financial and economic crisis, which negatively affected all areas of activity and the fall in demand for labour.

Some information about foreign workers employed in the Russian economy can be obtained from the development of data from regular surveys of the population on employment issues. Should be noted that, according to such surveys, the number of foreign citizens who came to the attention of the survey in 2012 was 259.5 thousand people, which does not correspond to their actual presence on the Russian labour market [1].

At the present stage, the problem of migrants adaptation and integration into the accepted Russia multiethnic space is studied comprehensively, considering ethno-social and conflict risks, gender specifics, and modernisation of management practices depending on emerging social challenges.

In general, modern scientific works on migration and diasporas focus not so much on the dangers and risks associated with the current large migrants flow, but on the potential and integration capabilities of the host society, which acts either as an "arena of aggression and danger", contributing to the emergence of a "gladiatorial" response; or as an effective adaptive metasystem, which successfully integrates the migrant into the general 
rhythm and culture thanks to working and wellestablished sociocultural mechanisms. Among them, we note the publications of researchers Abramson [2], Brubaker [3], devoted to diaspora aspects in the context of the Motherland culture and the attempts of migrants to "construct" it in a foreign land. The Ibrahim article [4] considers the political context of migration, which raises the issue of migration as a threat to the security of States in France, the UK and the EU examples.

Current research issues are also being developed by Russian sociologists S. Guzenina [5-6], who focused on the immigrant's sociocultural adaptation process, $\mathrm{T}$. Dmitrieva [7] and K. Arshin [8], who study migration policy and risk management mechanisms. A. Nazarov and E. Nazarova analyse the gender dimension of modern ethno-migration processes [9]. It should be noted that the study of this problem in Russian sociology already has a tradition and well-known authors, the most authoritative of which is Yu. Arutyunyan, V. Volokh, L. Drobizheva, I. Ivakhnyuk, A. Marshak [7,10-13].

\section{PROBLEM STATEMENT}

Data from regular surveys of the population on employment issues shows that foreign workers are more often employed in construction $(17.4 \%)$, retail and repair (19.5\%), hotel and restaurant management (5\%) than Russian citizens. On the contrary, the share of foreign citizens employed in such sectors as finance $(0.5 \%)$, real estate operations $(2.1 \%)$, public administration and insurance $(2.1 \%)$, education $(3.7 \%)$, health care $(3.1 \%)$ is less. According to employment issues surveys, more than $60 \%$ of foreign workers have a General primary education or lower [1]. Researchers also pay great attention to the question of the Russians attitude to labour migrants.

In September 2018, the Public Opinion Foundation (POM) surveyed 53 regions of the Russian Federation, with a total of 1,500 respondents aged 18 and older. The results of the study showed that the most acute problem of jobs lack due to labour migrants is felt by metropolis residents, in particular, Moscowite (54\%). In contrast, the majority of urban-type settlements residents, and cities up to 1 million, said that they do not have such a problem at all (49\%). This is because the majority of foreign workers seek to gain a foothold in Moscow due to the higher standard of living in the capital. According to experimental data, respondents believe that it is most appropriate to accept migrants only for jobs that do not require qualifications (street cleaners, movers, etc.). Such an opinion is shared by about $37 \%$ of Russian citizens. A significant part of respondents stated that it is worth taking migrants to any jobs where there is a shortage of personnel $(36 \%)$ since low-skilled labour is unattractive for the local population [14].
Karina Pipia, a researcher at the Levada centre, presented an interesting report at the expert discussion of the X Gaidar forum "Modern migration to Russia: a resource and a challenge", which was held on January 16, 2018. We can say that Russian respondents already have a specific stereotypical image of a migrant with a list of positive and negative qualities (fig. 1). A more detailed study by the Levada centre of the Russians negative attitude to migrants in August 2018 shows that the main negative feature of visitors from the CIS countries is their cheeky behaviour, unwillingness to speak Russian. Less than a quarter of respondents attributed the negative features of the fact that migrants take jobs, agreeing for low-pay.

A detailed study of the Russian citizens' attitude to labour migrants was conducted by the Russian Public Opinion Research Center on December 16, 2018 [16]. 1,600 respondents were interviewed by telephone and compared with the data from the 2005 and 2013 surveys. Based on comparing the results of different years, it can be concluded that in general, the attitude towards immigrants remains contradictory, and Russians are "rather negative" about the presence of foreign migrants in most areas. The most negative attitude of respondents to the employment of newcomers is in local authorities and self-government (74\% "against"), law enforcement (69\%), education (58\%), public transport (58\%), medicine $(51 \%)$. The presence of newcomers in the field of retail (food markets) is not approved by $40 \%$ of respondents. Respondents are more loyal to the fact that immigrants are employed in the service sector (64\%), utilities (62\% are "rather positive"), construction (49\%).

\section{AUTHOR'S RESEARCH AND DATA COLLECTION METHOD}

This article presents the results of the author's sociological study "the role of the region host community in the labour migrants sociocultural adaptation", conducted in April 2019 among TSU named after G. R. Derzhavin students (the sample consisted of 1-4 academic year students, including 19 boys and 96 girls aged 18 to 25 years). The method of data collection is a questionnaire survey. The sample is quota-based by age; the restriction was also mandatory training at Tambov State University named after G. R. Derzhavin.

\section{DATA ANALYSIS}

According to the data obtained, the Russians most positive emotions are caused by labour migrants from the Republic of Belarus (25\%), Ukraine (21\%), Germany $(16 \%)$ and Kazakhstan (15\%). Tambov residents are most critical to the entry to Russia of representatives of such countries as Tajikistan (15\%), Uzbekistan (14\%), the United States (11\%), and China (9\%). 


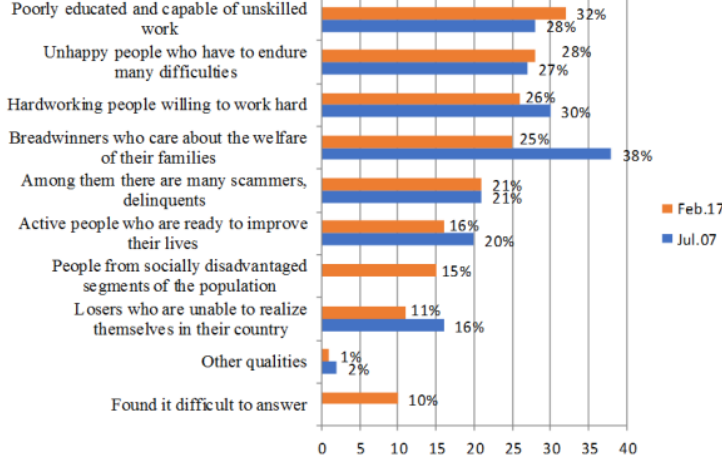

Figure 1 Distribution of respondents opinions about labour migrants (according to the Levada centre) [15].

At the same time, according to the respondents themselves, this opinion is formed among Russians about newcomers mainly due to the "sensational" headlines in the media of certain crimes, offences where the blame is most often a visiting migrant. According to the survey participants, the media have a significant impact on the emergence of interethnic and interfaith tensions in Russia. The majority of Tambov residents (78\%) agreed with this judgment (fig.2). However, the majority of respondents, as mentioned above, stated that their opinion about migrant workers is mainly influenced by information from various media outlets, rather than from personal observations.

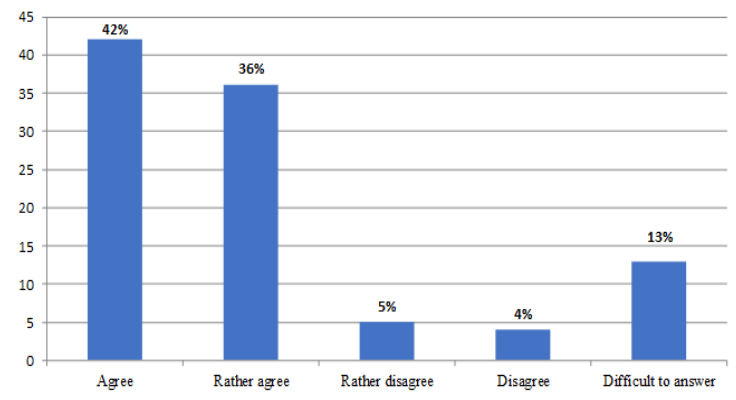

Figure 2 Distribution of answers to the question: "Do you agree that the media often increase and provoke interethnic and interfaith tensions in the country?"

Tambov young residents were asked for their opinion on the employment of migrants in various sectors of the economy.

The employment of migrants in low-skilled jobs was highly approved. Respondents are most loyal to the presence of labour migrants in public utilities and construction (84\% and $71 \%$, respectively, expressed approval to some extent). However, the employment of foreign workers in retail is not unequivocally approved. More than half of the respondents (54\%) have a negative attitude to the presence of migrant workers in the catering sector. As for the areas require high qualifications, respondents disapprove of the employment of newcomers in them (fig. 3).
The most negative attitude of young people is that immigrants are employed in local government $(81 \%)$, as well as in law enforcement (75\%).

At the same time, about a quarter of respondents expressed their approval of migrants employed in the medical sphere and education to some extent $(25 \%$ and $26 \%$, respectively).

According to $51 \%$ of respondents, entrepreneurs receive the most significant benefit from the use of migrant labour. Almost a quarter of students (24\%) chose the answer "officials". Interestingly, only $5 \%$ believe that the local population of Russia benefits most from immigrant labour (figure 4). At the same time, as noted above, respondents are aware that most of the jobs in lowpaid areas that are not in demand among local workers are occupied by foreign workers, and they attribute this fact to the undoubted advantages of labour migration.

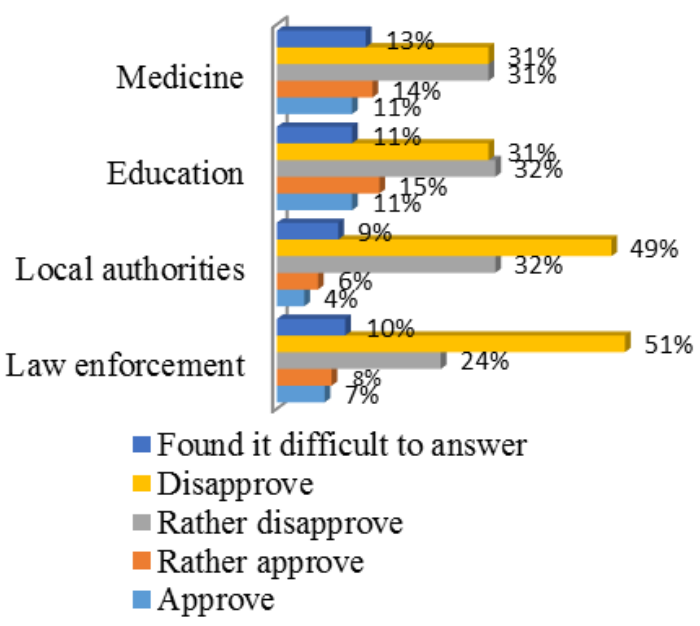

Figure 3 The attitude of Tambov students to the migrants with high qualifications employment in the economy.

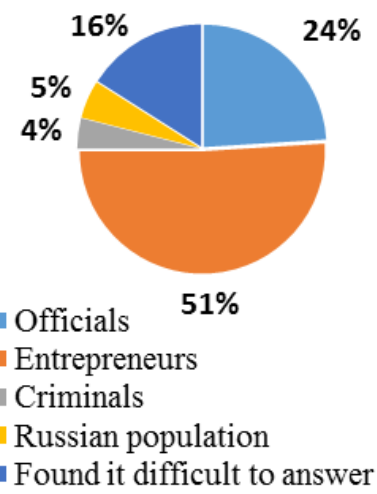

Figure 4 Distribution of respondents answers to the question: "Who, in your opinion, is most profitable to use migrant labour in the Russian economy?"

In conclusion, we note that the difficulties for young Tambov residents in conducting a sociological survey, as well as for most of the Russians, caused, first of all, 
questions about changes in the situation with the regulation of labour migration. $45 \%$ of respondents can't express their opinion on this issue. At the same time, more than a third of respondents $(34 \%)$ note that there are no changes in this area.

\section{CONCLUSIONS}

Based on the study results, it can be argued that the following conclusions regarding the collective opinions of Russians regarding migrants are quite justified:

- most of the survey participants admit that migrants make up for the lack of workers in low-paid jobs that are unattractive for locals, but a significant part of young people are concerned about competition with newcomers in the labour market;

- considering the positive consequences of the foreign workers' presence, the majority of respondents have a rather negative attitude to labour immigration to Russia;

- there is a more negative attitude of respondents to Tajiks, Uzbeks, Kyrgyz, as well as representatives of the North Caucasus who come to work. This fact is related to the negative image of representatives of these ethnic groups formed in the Russian media;

- a significant part of the respondents does not approve the labour migrants presence in areas that require high qualifications, as they see among the main qualities characteristic of newcomers, lack of education and unwillingness to get acquainted with the language and culture of the host society. This factor serves as the basis for a biased attitude towards labour migrants not only in the labour market but also in other spheres of public life, which, in turn, creates difficulties for their sociocultural adaptation.

\section{REFERENCES}

[1] N.V. Mkrtchyan, M.B. Denisenko, O.S. Chudinovskikh, Temporary labour migrants in Russia, Electronic magazine Demoscope Weekly, 579-580, 2013.

[2] Y. Abramson, Making a homeland, constructing a diaspora: The case of Taglit-Birthright Israel, Polit. Geography 58 (2017) 14-23.

[3] R. Brubaker, The "diaspora" diaspora, Ethnic and racial studies 28(1) (2005) 1-19.

[4] M. Ibrahim, The Securitization of Migration: A Racial Discourse, Int. migrat 5 (2005) 163-187.

[5] S. Guzenina, N. Volkova, N. Iakushkina, "Own""alien": on sociocultural adaptation of the foreign russian community, EpSBS The European Proceedings of Social \& Behavioural Sciences, SCTMG Vol. 92 (2020) 1872-1878.
[6] S.V. Guzenina, A.L. Marshak, Transformation of the concept of "homeland" in the process of sociocultural adaptation of immigrants. S.V. Guzenina, A.L. Marshak, SEARCH: Politics. Social studies, Art. Sociology, Culture, Scientific journal, Moscow 1 (2019) 58-64.

[7] V.A. Volokh, T.N. Dmitrieva, Institutional forms of dialogue between the government and civil society in the context of migrant integration policy (on the example of Moscow), Theories and problems of political research Vol. 6 Iss. 2A (2017) 420-431.

[8] K. Arshin, Risk management as a tool for migration regulating, EpSBS The European Proceedings of Social \& Behavioural Sciences, SCTMG Vol. 92 (2020) 97-104.

[9] A.D. Nazarov, E.A. Nazarova, The gender dimension of modern ethno-migration processes: theoretical, methodological and communicative aspects, A.D. Nazarov, E.A. Nazarova, Kommunikologiya Vol. 3 Iss. 6 (2015) 48-66.

[10] Yu.V. Arutyunyan, On the potential of interethnic integration in the Moscow megapolis, Sociological research 1 (2005) 26-40.

[11] L.M. Drobizheva, Civil identity as a condition for weakening ethnic negativism, Russian world Vol. 26 Iss. 1 (2017) 7-31.

[12] I.V. Ivakhnyuk, Some methodological and practical issues of the policy of integration of migrants in Russia Ivakhnyuk, Migrants integration: is it possible in modern society?, series International population migration: Russia and the modern world, Moscow University Press (M.), Vol. 29, pp. 8-28.

[13] A.L. Marshak, S.V. Guzenina, Sociocultural practices of adaptation of immigrants: on the question of the integration potential of the host society, A.L. Marshak, S.V. Guzenina, Sociological science and social practice: a scientific journal 4 (2019) 139-153.

[14] Attitude to labour migrants [electronic resource]. Retrieved from: https://fom.ru/ Nastroeniya/14114 (access date 15.11.2020).

[15] Presentation of the report "migrant phobia in Russian public opinion" [electronic resource]. Retrieved from: https://www.levada.ru/2019/01/18/prezentatsiyamigrantofobiya-v-rossijskom-obshestvennommnenii/ (access date 15.11.2020).

[16] Immigration to Russia: good or bad? [electronic resource]. Retrieved from: https://wciom.ru/index.php?id=236\&uid=9487 (access date: 15.11.2020). 